\title{
Individual differences in behavioral and cardiovascular reactivity to emotive stimuli and their relationship to cognitive flexibility in a primate model of trait anxiety
}

\author{
Yoshiro Shiba ${ }^{1,2 *}$, Andrea M. Santangelo ${ }^{1,2}$, Katrin Braesicke ${ }^{1,2}$, Carmen Agustín-Pavón $^{1,2+}$, \\ Gemma Cockcroft $^{2,3}$, Mark Haggard ${ }^{3}$ and Angela C. Roberts ${ }^{1,2}$
}

\author{
${ }^{1}$ Department of Physiology, Development and Neuroscience, University of Cambridge, Cambridge, UK \\ ${ }^{2}$ Behavioural and Clinical Neuroscience Institute, University of Cambridge, Cambridge, UK \\ ${ }^{3}$ Department of Psychology, University of Cambridge, Cambridge, UK
}

\author{
Edited by: \\ Benjamin Adam Samuels, Columbia \\ University, USA \\ Reviewed by: \\ Agnes Lacreuse, University of \\ Massachusetts, USA \\ Jocelyne Bachevalier, Emory \\ University, USA \\ *Correspondence: \\ Yoshiro Shiba, Department of \\ Physiology, Development and \\ Neuroscience, University of \\ Cambridge, Downing Street, \\ Cambridge CB2 3DY, UK \\ e-mail:ys341@cam.ac.uk \\ ${ }^{\dagger}$ Present address: \\ Carmen Agustín-Pavón, Department \\ of Life Sciences, Imperial College \\ London, South Kensington Campus, \\ London, UK
}

High trait anxiety is a risk factor for the development of anxiety disorders. Like the disorders themselves high trait anxiety has marked phenotypic variation at the level of symptomatology and neural circuits, suggesting that there may be different symptoms and distinct neural circuits associated with risk for these disorders. To address these issues, it is essential to develop reliable animal models of trait anxiety in a non-human primate whose brain bears structural and functional similarity to humans. The present study investigated individual variation in responsivity to fearful and anxiety provoking stimuli in the common marmoset monkey. Seven out of 27 animals failed to display discriminative, conditioned cardiovascular and behavioral responses on an auditory fear discrimination task, similar to that seen in high anxious humans and rodents. Their heightened emotionality to a rubber snake was consistent with the hypothesis that they were high in trait-like anxiety. Evidence for phenotypic variation in the high anxiety group was provided by the finding that discrimination failure was predicted early in conditioning by either hyper-vigilant scanning to the cues or a reduction in blood pressure to the context, i.e., test apparatus. Given that high trait anxiety in humans can be associated with altered prefrontal cognitive functioning and previously we implicated the marmoset anterior orbitofrontal (antOFC) and ventrolateral prefrontal cortex (VIPFC) in negative emotion regulation, we also tested the marmosets on two tests of cognitive flexibility differentially dependent on these two regions. While the high anxious group did not differ overall in their perseverative performance, the two distinct phenotypes were differentially correlated with reduced perseverative responding on the OFC- and VIPFC-dependent flexibility tests. Together, this study provides a new model of trait anxiety in marmosets amenable to analysis of phenotypic variation and neural circuitry.

Keywords: trait anxiety, fear generalization, marmoset, cognitive flexibility, prefrontal cortex, biomarkers

\section{INTRODUCTION}

Fear and anxiety are adaptive responses, elicited by explicit and uncertain threat, respectively. However, in excess, as in humans with high trait anxiety, they are a significant risk factor for developing mood and anxiety disorders (Chambers et al., 2004; Sandi and Richter-Levin, 2009). Trait anxiety refers to a general tendency to perceive and react negatively in a wide variety of stressful situations (Gaudry et al., 1975). High trait-anxious individuals show enhanced attentional bias toward negative cues (Bradley and Mogg, 1999; Cisler and Koster, 2010), are more likely to interpret emotionally ambiguous stimuli as threatening (Mathews et al., 1989; Richards et al., 2002) and display impaired performance on prefrontal-dependent cognitive control tasks (Bishop, 2009; Visu-Petra et al., 2012). Consistent with these findings, a high anxiety phenotype has been associated with decreased prefrontal activity, increased amygdala activity (Indovina et al., 2011) and reduced functional (Bishop, 2007; Hahn et al., 2011) and structural connectivity between the two (Kim and Whalen, 2009), features common with a variety of anxiety disorders, including posttraumatic stress disorder (Shin et al., 2005; Killgore et al., 2013; Stevens et al., 2013), panic disorder (Thomas et al., 2001; Killgore et al., 2013) and specific phobia (Ahs et al., 2009; Killgore et al., 2013). Thus, the study of trait anxiety has the potential to provide important insights into the etiology and treatment of anxiety disorders (Sandi and Richter-Levin, 2009; Indovina et al., 2011).

Marked individual differences in responsivity to fearful- and anxiety-provoking stimuli have been reported in other animals, including rodents (Duvarci et al., 2009) and monkeys (Nelson et al., 2003). The development of these non-human models will be essential for establishing the causal relationship between the observed alterations in neural circuitry in high trait anxious individuals and their behavioral phenotype. In particular, it is important to develop models in monkeys in which prefrontal structure and connectivity patterns are similar to those in humans 
(Price, 1999; Burman et al., 2006; Roberts et al., 2007; Burman and Rosa, 2009; Yeterian et al., 2012). The common marmoset is a well established primate model for cognitive neuroscience and an emerging model for molecular studies since the completion of its genome and the first transgenic marmoset (Sasaki et al., 2009), making it an ideal species for studying the interaction between genes, environment and brain development in the context of behavioral risk factors for affective disorders. Thus, the present study investigated individual differences in the responsivity of this species to fearful and anxiety-provoking stimuli. Differences in fear conditioning, in particular, discriminatory fear conditioning, are associated with high trait anxiety in both humans (Grillon, 2002) and rats (Duvarci et al., 2009), and so marmosets received Pavlovian discriminatory fear conditioning, whereby one of two auditory cues was associated with aversive loud noise (Experiment 1). Simultaneous recording of cardiovascular activity and behavior provided a comprehensive measure of the emotional state. Their observed individual differences in cardiovascular and behavioral responsivity were then compared to their performance in another anxiety-provoking context, namely, exposure to a rubber snake (Barros et al., 2002; Izquierdo and Murray, 2004; Clara et al., 2008; Machado et al., 2009) (Experiment 2).

Finally, we also determined their cognitive performance on two distinct tests of prefrontal function. Whilst impairments in prefrontal function have been commonly reported in high trait anxious humans (Bishop, 2009; Visu-Petra et al., 2012), improvements have also been reported (Belsky et al., 2009; Homberg and Lesch, 2011), particularly in the absence of anxiety provoking stimuli. However, to our knowledge, there have been no reports of the cognitive abilities of high and low trait anxious rodents or monkeys. Thus, given our previous findings that implicated both the antOFC and vlPFC in the regulation of fear and anxiety (Agustín-Pavón et al., 2012), we investigated the animal's performance on two appetitive cognitive flexibility tests differentially dependent upon these two ventral PFC regions (Wallis et al., 2001; Man et al., 2009).

\section{MATERIALS AND METHODS GENERAL EXPERIMENTAL DESIGN}

Figure 1 depicts the overall schedule and subject details. All procedures were approved by an Ethical Review Committee from the University of Cambridge and conducted in accordance with the project and personal licenses held by the authors under the UK Animals (Scientific Procedures) Act of 1986.

\section{EXPERIMENT 1: INDIVIDUAL DIFFERENCES IN AVERSIVE DISCRIMINATIVE PAVLOVIAN CONDITIONING Subjects}

Twenty-seven experimentally naïve common marmosets (Callithrix jacchus, 14 females and 13 males, average age 2.3 years ranging 1.6-3.1) were used (Figure 1). The animals were matured young adults in terms of both reproduction (Tardif and Smucny, 2003) and PFC morphology (Oga et al., 2013). The animals were housed in male/female pairs in rooms with controlled humidity and temperature and with a 12-h light/dark cycle. They were fed whole meal bread, hard-boiled egg, and a piece of fruit after testing. This diet was supplemented with additional fruit and nuts on the week ends. Water was available ad libitum.

\section{Implantation of telemetry transmitter for cardiovascular recording}

To measure heart rate (HR) and blood pressure (BP) changes remotely in animals, a PhysioTel Telemetry System (Data Sciences, St. Paul, Minnesota) was used. A telemetry transmitter (TA11PAC40) was implanted into the abdominal cavity, and the probe catheter was inserted into the descending aorta as described previously (Braesicke et al., 2005).

\section{Mild aversive pavlovian discriminative conditioning}

Test apparatus. Behavioral testing took place within a soundattenuated test apparatus. Each subject was transported from the home cage to the apparatus in a clear Perspex box. The carrying box, with the subject, was then fitted into the internal frame of the apparatus; a detailed illustration is given in (Mikheenko et al., 2010). Cardiovascular data were collected by

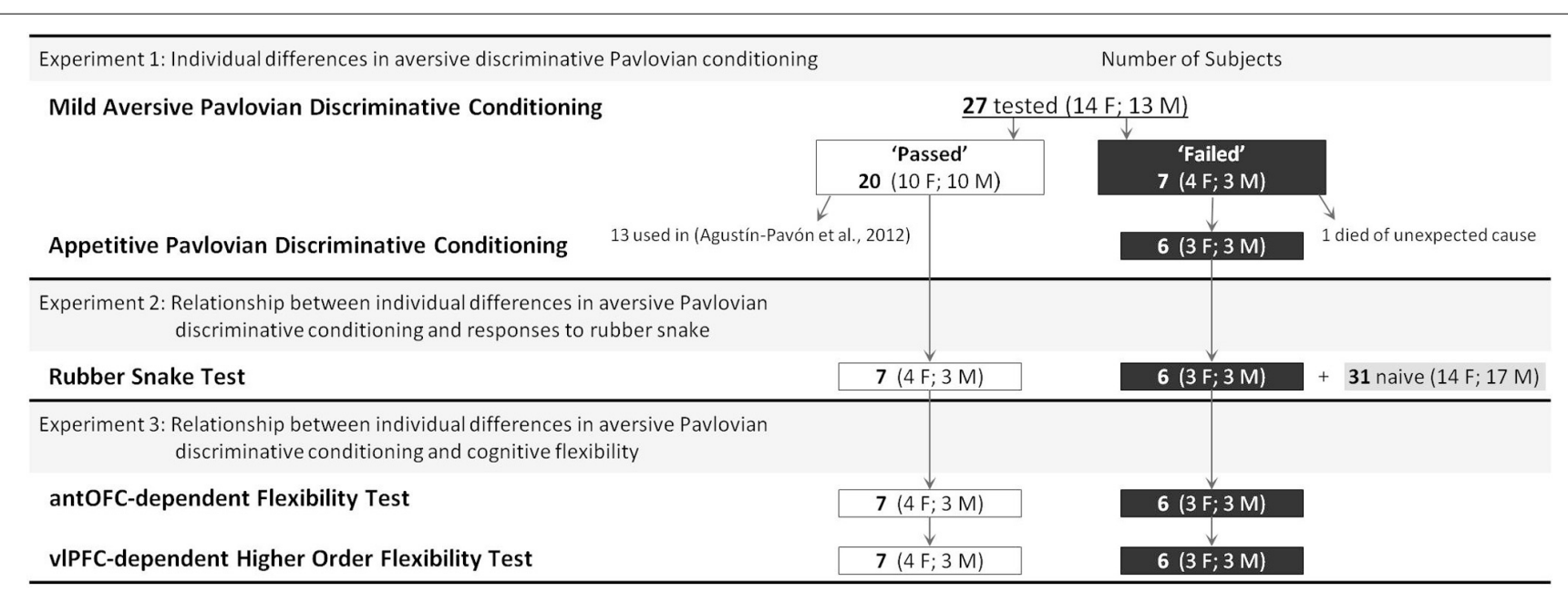

FIGURE 1 | General Experimental Schedule and Number of Subjects used for each Experiment. 
the telemetric receiver (RPC-1, Data Sciences) placed underneath the floor of the internal frame. Sound conditioning stimuli were generated in AdobeAudition software (version 1.5) and played through a computer-controlled loudspeaker (Biotronix, UK). An unconditioned aversive noise stimulus was generated by a siren controller box (Electronics Development Group, Engineering Department, University of Cambridge) and played through a computer-controlled siren speaker (Biotronix, UK). The onset and offset of the light and sounds were controlled by Whisker device control software (Cardinal and Aitken, 2010).

\section{Test procedures.}

Orienting. Once the animals were habituated to the apparatus, showing relatively stable $\mathrm{HR}$ across three sessions, they were moved to the orienting sessions. Animals received two orienting sessions, in which two novel sounds, a $4 \mathrm{kHz}$ tone and a clicker at $70 \mathrm{~dB}$ [the "to-be" conditioned stimuli (CSs)], were each presented pseudorandomly for a duration of $20 \mathrm{~s}$, four times a session, on a variable inter-CS interval (icsi) schedule (120-180 s). The aim of these sessions was to monitor the behavioral and autonomic reactions of the animals toward the novel stimuli. The stimulus that elicited the smaller behavioral and autonomic reaction was chosen as the $\mathrm{CS}^{+}$, and the one that elicited the larger reaction became the $\mathrm{CS}^{-}$, thus avoiding any stimulus preparedness (Agustín-Pavón et al., 2012).

Conditioning. Following the orienting, the animals received Pavlovian conditioning in which one of two auditory cues $\left(\mathrm{CS}^{+}\right)$ was associated with a burst of mildly aversive loud noise [unconditioned stimulus ( $\mathrm{US}^{+}$), $120 \mathrm{~dB}, 0.3-0.7 \mathrm{~s}$ ] and the other $\left(\mathrm{CS}^{-}\right)$ with a non-aversive, very brief period of "light off" (US'- $0.5 \mathrm{~s}$ ) as described fully in Figure 2A. The brief period of "light off" following the $\mathrm{CS}^{-}$was used to increase the overall discriminative ability of the two CSs (Fedorchak and Bolles, 1986). In a session, $4 \mathrm{CS}^{+} \mathrm{s}$ and $4 \mathrm{CS}^{-} \mathrm{s}$ were pseudorandomly presented. The schedule and parameters were otherwise identical to those used in orienting. Each animal was given one session a day until they acquired the discriminative conditioning criterion (see below) or until they had received 30 sessions, whichever occurred first. The former was considered a successful, and the latter a failed discrimination.

Discriminative criterion. Each animal was given one session a day until vigilance behavior and heart rate during the $\mathrm{CS}^{+}$(compared to baseline (BL)) was significantly greater than that to the $\mathrm{CS}^{-}$ (compared to BL) over three consecutive sessions (conditioning criterion) (Agustín-Pavón et al., 2012).

Behavioral and cardiovascular measurement. Behaviors during testing were video-recorded and subsequently scored by a research technician (GC) unaware of the experimental conditions and whether animals went on to pass or fail the discrimination. In addition, to assess the inter-rater reliability for the scoring, three sessions from each of two animals were randomly selected and scored by another experienced scorer. The intra-class correlation coefficient (ICC) was $0.75\left[F_{(35)}=6.93, p<0.001\right]$ which is within the good range of reliability (Cyr and Francis, 1992).
The $\mathrm{CS}^{+}$-related behaviors [typically displayed by marmosets in response to simple Pavlovian conditioning (Mikheenko et al., 2010)] were treated as a single measure of "vigilant scanning" and included attentive visual search of surroundings accompanied by tense postures marked by forward extension of body/head and rearing. The duration of the behavior displayed during the BL and CS periods was scored using a program written in QuickBASIC 4.5.

$\mathrm{BP}$ (systolic and diastolic) and HR data were recorded on a PC with data acquisition software Spike2 (version 7.01, Cambridge Electronic Design). Outliers (BP values $>400 \mathrm{mmHg}$ or $<0 \mathrm{mmHg}$, or other abnormal spikes) were removed using an algorithm written in Visual Basic, and systolic and diastolic BP events were extracted as local minima and maxima for each heartbeat cycle as described previously (Agustín-Pavón et al., 2012). $\mathrm{HR}$ was the more reliable autonomic response to the $\mathrm{CS}^{+}$both within and between animals (Mikheenko et al., 2010) and so together with behavior, was used for the discriminative criterion (Figure 2A).

\section{Appetitive Pavlovian discriminative conditioning}

To rule out the possibility that any failure in fear discriminative conditioning was due to a general impairment in learning ability, six ( 3 female; 3 male) of the seven subjects that failed (one animal died of unexpected causes) were tested on an appetitive Pavlovian discriminative conditioning paradigm (Reekie et al., 2008). A similar experimental setting to that of the aversive conditioning paradigm was used, with the sound that was used as $\mathrm{CS}^{+}$in the aversive conditioning paradigm staying as $\mathrm{CS}^{+}$and the $\mathrm{CS}^{-}$staying as $\mathrm{CS}^{-}$. However, instead of aversive loud noise, the $\mathrm{CS}^{+}$was associated with reward (half-full box of marshmallows, $\mathrm{US}^{+}$) and the $\mathrm{CS}^{-}$with the absence of reward (empty food-box, US ${ }^{-}$). Twothirds of the sessions contained a $\mathrm{CS}^{+}$along with $0-2 \mathrm{CS}^{-}$s. The remainder of the sessions contained 1-2 $\mathrm{CS}^{-} \mathrm{s}$ only. The length of the CSs, icsi, and BL periods were the same as for the fear discrimination paradigm (see Figure 2A). The period of access to either the empty or half-full food-box was 2 min. Discriminative criterion was defined as significantly greater "head jerk" behavior (CS-directed orienting responses consisting of a flick/snap of the head) (Reekie et al., 2008) and BP to six consecutive $\mathrm{CS}^{+} \mathrm{s}$ compared to the intervening 6-14 $\mathrm{CS}^{-} \mathrm{s}$.

\section{Statistical analysis}

All cardiovascular and behavioral data were analyzed with $t$-test, mixed design ANOVA and logistic regression analysis (SPSS versions 17-21). The behavioral data in the orienting session showed a violation of normality assumption (detected by ShapiroWilk test), therefore log transformation was performed prior to hypothesis testing.

\section{EXPERIMENT 2: RELATIONSHIP BETWEEN INDIVIDUAL DIFFERENCES IN AVERSIVE PAVLOVIAN DISCRIMINATIVE CONDITIONING AND EMOTIONAL RESPONSES TO A RUBBER SNAKE \\ Rubber snake test}

Subjects. Seven "passed" (4 female, 3 male) and six "failed" (3 female, 3 male) animals from Experiment 1 (see Figure 1). The remaining animals from Experiment 1 went on to receive lesions 
A Mild Aversive Pavlovian Discriminative Conditioning: Experimental procedure
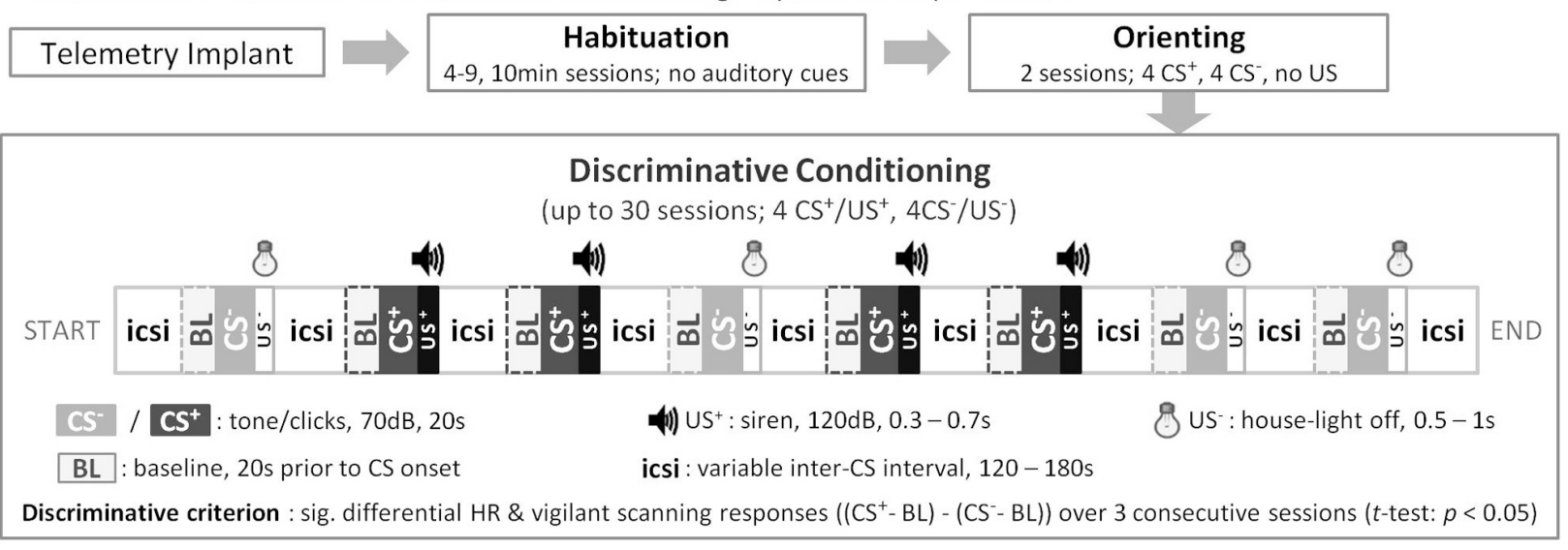

Bi Rubber Snake Test: Test Quadrant \& Zones

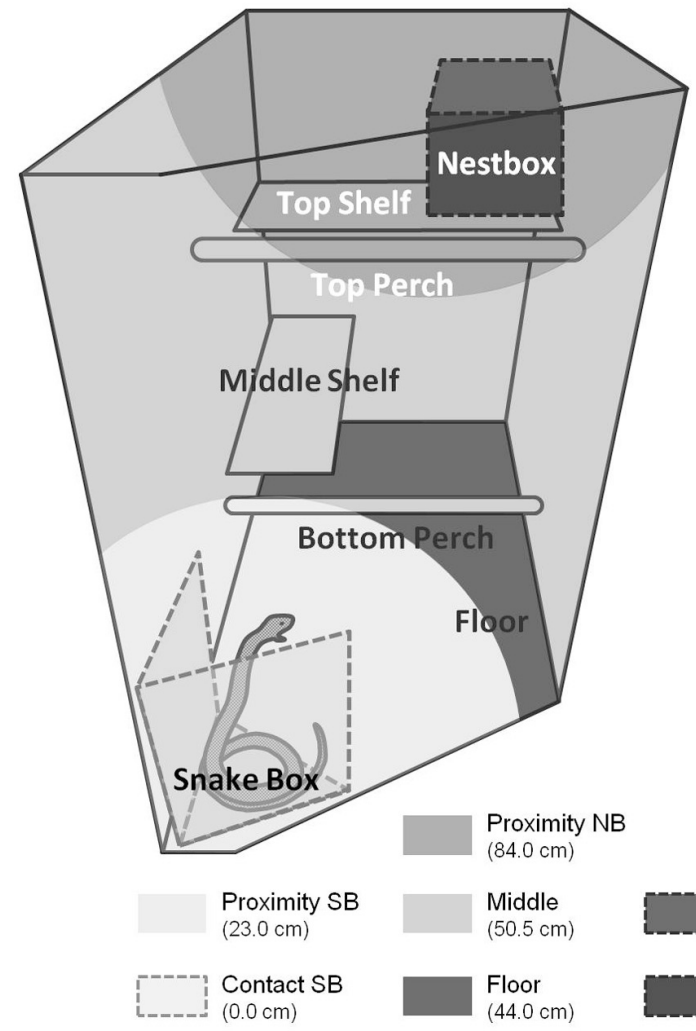

Bii Experimental Procedure

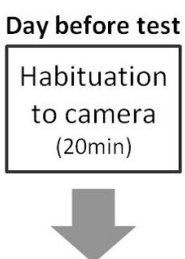

Test day

Separated (5min)

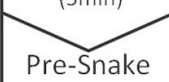

(empty box)

$(5 \mathrm{~min})$

Snake

$(5 \mathrm{~min})$

Post-Snake

(empty box)

(5min)
FIGURE 2 | Experimental Procedures. (A) Pre-training and testing on the mild aversive Pavlovian discriminative conditioning paradigm. (B) Rubber snake test. (Bi) Top right-hand quadrant of the home cage viewed from the upper front corner and (Bii) Experimental procedure. (C) Cognitive flexibility tests. (Ci) In the antOFC-dependent flexibility test, to obtain the food reward, the subject was required to choose the box with low-incentive pellets whilst inhibiting their prepotent response for the high-incentive marshmallows. (Cii) In the vIPFC-dependent higher order flexibility test, the subject was required to transfer the acquired strategy from the opaque to the transparent box while inhibiting reaching directly to the now visible reward. "Front" denotes the surface of the box that was immediately facing the marmoset. of the prefrontal cortex for another study (Agustín-Pavón et al., 2012).

Stimulus. A model snake made of rubber was used as a stimulus. It resembled a cobra and was coiled with its head raised
$(27 \mathrm{~cm}$ in height) and dark brownish in color with black stripes. A triangular prism box made of opaque white Perspex $(26 \times 26 \times$ $29.5 \mathrm{~cm}$ triangle sides $\times 30 \mathrm{~cm}$ high) contained the rubber snake. By removing the sliding door, the snake could be revealed to the subject. The box was designed to conceal the snake from all 
marmosets except the target subject. The animals had never seen the snake or the box before the experiment.

Test procedures. Testing took place in the home cage following a habituation session the day before, which was identical to the test session except that the box did not contain the rubber snake. On the test session, the subject was first separated from the cage mate into the upper right quadrant $(92 \mathrm{~cm}$ high $\times 60 \mathrm{~cm}$ wide $\times 98 \mathrm{~cm}$ deep, Figure $2 \mathbf{B i}$ ), preventing visual contact. The 20 -min session was divided into four 5-min phases: "Separated" (only camera and microphone were present), "Pre-snake" (an empty box was placed in the test quadrant), "Snake" (the empty box was replaced with a box containing the rubber snake), and "Post-snake" (an empty box) (Figure 2Bii). Testing took place between 12:00 and 13:00 on week days. The order of testing was randomized across the animals.

Behavioral measurements. Video-recorded behaviors were scored by a person blind to the experimental conditions using a quantitative analysis program (JWatcher, Version 1.01). The vocalizations were observed only in the presence of the threat stimulus. They were recorded by a shotgun microphone (Pulse, NPM702) ensuring that the target animal's calls could easily be distinguished from any other animals' calls in the room. The calls were analyzed with sound spectrogram (Syrinx-PC software, Version 2.61). Behavioral parameters included:

(1) Average distance from the snake. The test quadrant was divided into seven zones based on the proximity to the snake (Figure 2Bi). The proportion of time an animal spent in each zone over the 5-min phase was scored. The average distance was obtained by multiplying these proportions with the mean distance of each zone from the snake and summing the products.

(2) Locomotion. The proportion of time an animal spent in translational movement over the 5-min phase. The translational movement was registered when an animal altered its body position using all four limbs.

(3) Stare duration. The proportion of time an animal spent staring at the model snake. Staring was defined as any time when an animal's eyes and head were oriented directly toward the model snake.

(4) Stare frequency. The number of discrete occasions an animal stared at the model snake.

(5) Head-cock. Number of head movements from side to side while the animal's attention is directed to the model snake. This behavior has been reported as an observational behavior (Barros et al., 2002).

(6) Tsik call. A short and loud "tsik" sound. It has been reported as an alarm/mobbing call (Cross and Rogers, 2006; Bezerra and Souto, 2008; Clara et al., 2008; Cagni et al., 2011).

(7) Tsik-egg call. A tsik call closely followed by an egg call (a short call with a few harmonics). This call is associated with vigilance behavior (Pistorio et al., 2006; Bezerra and Souto, 2008).

Statistical analysis. All analyses were performed using SPSS (version 17-21). To provide a thorough characterization of the pattern of behavior displayed to the rubber snake and to maximize the sample size available for the subsequent principal component analysis (PCA), test data from additional 31 experimentally naïve marmosets (14 female, 17 male) were analyzed alongside the 13 "passed" and "failed" animals (see Figure 1). The latter fell within the observed range. For the "Snake" phase, PCA was performed $(n=44)$ to reduce the separate but correlated measures into weighted composites that reflect underlying psychological dimensions (Field, 2009). Component scores for individual animals were calculated using Anderson-Rubin method (Field, 2009) and used for subsequent mixed-design ANOVA and multiple regression $(n=13)$. Adequacy of sample size for PCA was assessed by the Kaiser-Meyer-Olin test, which returned an acceptable value of 0.64 (Field, 2009).

\section{EXPERIMENT 3: RELATIONSHIP BETWEEN INDIVIDUAL DIFFERENCES IN AVERSIVE PAVLOVIAN DISCRIMINATIVE CONDITIONING AND COGNITIVE FLEXIBILITY \\ Subjects}

Seven "passed" ( 4 female, 3 male) and six "failed" ( 3 female, 3 male) animals (see Figure 1).

\section{antOFC-dependent flexibility test}

Animals were tested in a Wisconsin General Test Apparatus (WGTA) as previously described (Man et al., 2009). In each test trial (30 trials/session) they were presented with a choice between high-incentive marshmallows and low-incentive food pellets within transparent Perspex boxes. A response (touch) to either box resulted in the box being withdrawn, revealing the food well underneath. A response to the low-incentive, but not the high-incentive food box, was associated with food reward (syrup bread); thus, the subject was required to inhibit the prepotent response tendency to choose the high-incentive stimulus (Figure 2Ci). Testing was video-recorded and subsequently scored. Signal detection theory (Macmillan and Creelman, 2005) was used to classify the type of error responses into "perseverative" (responding to the incorrect stimulus significantly above chance) and "non-perseverative" (responding to the incorrect stimulus at or below chance) for each block of 10 trials (Clarke et al., 2004; Man et al., 2009).

\section{vIPFC-dependent higher order flexibility test}

Animals were tested in the WGTA as previously described (Wallis et al., 2001). Briefly, animals were first trained, on each trial, to touch and check each of three doors of a black opaque Perspex box in order to locate the unlocked door and retrieve the food reward (a piece of marshmallow) from within. Only one of the three doors of the box was unlocked on each trial, and success was defined as having found the unlocked door without having checked any door more than once. Having learned this strategy and performed 16 successful trials within a 21-trial session for four consecutive sessions, they progressed to the two test sessions. These were identical to training, except that a transparent box replaced the black opaque box. Although the subject could now "see" the reward along their direct line of sight (i.e., through the front door), the same strategy as before was required to obtain the reward (Figure 2Cii). A reach was defined as making contact 
with the door and then taking the hand away again. A failed reach (directly toward the now visible reward) to the locked front door was denoted a "barrier reach" error (Wallis et al., 2001), and was considered a sign of perseveration. Errors to the locked side door were denoted "non-barrier" reach errors.

\section{Statistical analysis}

Errors across groups were analyzed using $t$-test and factorial ANOVA. Correlation analysis and the Williams and Steiger test were performed to compare the measures from aversive discriminative conditioning with cognitive test performance.

\section{RESULTS \\ INDIVIDUAL DIFFERENCES IN THE ABILITY TO ACOUIRE MILD AVERSIVE PAVLOVIAN DISCRIMINATIVE CONDITIONING}

After repeated exposure to the $\mathrm{CS}^{+}$associated with the aversive loud noise and to the $\mathrm{CS}^{-}$associated with the neutral stimulus, 20 out of 27 animals (74\%) developed significant discriminative conditioned behavioral $\left[\mathrm{CS}^{+}\right.$vs. $\mathrm{CS}^{-}, t_{(22)}>2.14, p<0.05$, for each animal] (Supplementary Table 1, "Passed") and cardiovascular responses $\left[t_{(22)}>2.12, p<0.05\right.$, for each animal] (Supplementary Table 2, "Passed"), between the 6th and 28th session, thus passing the criterion. The remaining seven animals (26\%), however, failed to attain the discriminative conditioned responses even after 30 sessions (exposure to $120 \mathrm{CS}^{+} \mathrm{s}$ and $\mathrm{CS}^{-} \mathrm{s}$ each) [behavior: $t_{(22)}<1.21$, HR: $t_{(22)}<1.49$, for each animal] (Figure 3A, Supplementary Tables 1, 2, "Failed"). We compared the mean vigilant scanning toward the CSs in the three criterion sessions of the "passed" group with the final three sessions (i.e., 28-30) of the "failed" group. This showed that the "passed" group displayed significantly greater vigilance to the $\mathrm{CS}^{+}$compared to the $\mathrm{CS}^{-}$, whereas vigilance was heightened but did not differ between the CSs in the "failed" group [Two-Way factorial ANOVA: Group $\times$ CS, $F_{(1,25)}=47.29, p<0.001$; post-hoc pairwise comparison of $\mathrm{CS}^{+}$vs. $\mathrm{CS}^{-}$for "passed," $F_{(1,25)}=106.95$, $p<0.001$, for "failed," $F_{(1,25)}=3.50, p=0.073$ ] (Figure 3Bi). Similarly, the "passed" but not the "failed" group also showed heightened HR during the $\mathrm{CS}^{+}$compared to the $\mathrm{CS}^{-}$[Group $\times$ $\mathrm{CS}, F_{(1,25)}=46.04, p<0.001$; post-hoc pairwise comparison of $\mathrm{CS}^{+}$vs. CS ${ }^{-}$, for "passed," $F_{(1,25)}=115.72, p<0.001$, for "failed," $\left.F_{(1,25)}=2.31, p=0.141\right]$ (Figure 3Bii).

\section{CARDIOVASCULAR AND BEHAVIORAL RESPONSES EARLY IN TRAINING TOGETHER PREDICT EVENTUAL SUCCESS OR FAILURE IN AVERSIVE DISCRIMINATIVE CONDITIONING}

Next, we determined whether individual differences in behavioral and cardiovascular reactivity in the early sessions were associated with eventual success or failure to display discriminative conditioning. This comparison was made at a time-point well before the majority of animals had shown any evidence of cardiovascular or behavioral conditioning and enabled us to see whether there were any early behavioral or cardiovascular biomarkers that would predict eventual discriminative failure. Responses during cue presentation (CSs) and BL were averaged across the first three sessions and compared between the "passed" and "failed" groups. This revealed that animals in the "failed" group displayed significantly greater vigilance responses to both
CSs [Two-Way factorial ANOVA (Group $\times$ CS): Group, $F_{(1,25)}=$ 6.71, $p<0.05$ ] (Figure 3Ci, Supplementary Figure 1A) and significantly greater $\mathrm{HR}$ responses to the $\mathrm{CS}^{-}$compared to those that passed ("passed": Mean $(M)=2.37$, Standard Error of Mean $(\mathrm{SEM})=1.72$, "failed": $M=14.14, \mathrm{SEM}=5.34)$ [Group $\times$ CS: $F_{(1,25)}=11.57, p<0.01$; post-hoc pairwise comparison: "passed" vs. "failed," for $\mathrm{CS}^{+}, F_{(1,25)}=0.25, p=0.619$, for $\mathrm{CS}^{-}, F_{(1,25)}=7.75, p<0.01$ ] (Supplementary Figure 1B). Such increased vigilance and HR to the CSs were not seen in the preconditioning orienting sessions in the absence of aversive stimulus although there was a trend for increased vigilant scanning to the CSs [behavior: $F_{(1,25)}=3.26, p=0.08, \mathrm{HR}: F_{(1,25)}=0.62$, $p=0.44]$. Whilst there were no differences between the groups in $\mathrm{BL}$ cardiovascular responses in the first three sessions, there was a noticeable decline in BL HR (bradycardia) and BP across the next few sessions, reaching a nadir by session 9 , in the animals that failed the discrimination (Supplementary Figures 1C,D). The slope of the best fitting line over the mean of three, three-session blocks (1-3, 4-6, 7-9) was used to quantify this decline; the negative value indicating reduction in BP [One-Way ANOVA of the slopes across sessions: "passed" vs. "failed," for BP, $F_{(1,25)}=$ 7.27, $p<0.05$, for HR, $F_{(1,25)}=4.24, p=0.05$ ] (Figure 3Cii). No such baseline differences were observed in vigilant scanning $\left[F_{(1,25)}=1.60, p=0.218\right]$.

To assess how reliably the responses in the early sessions predicted the eventual success or failure of the animals in discriminative conditioning, a binary logistic regression analysis was performed using, as predictor variables, all behavioral and cardiovascular measures that showed highly significant group differences in the early sessions (CS vigilant scanning, $\mathrm{HR} \mathrm{CS}^{-}, \mathrm{BL}$ hypotension). The final model $\left[\chi_{(2)}^{2}=13.12, p<0.001\right.$; backward stepwise strategy] retained two of the variables, namely, CS vigilant scanning and BL hypotension as significant predictors (Figure 3D).

\section{ANIMALS THAT FAIL TO ACQUIRE AVERSIVE DISCRIMINATIVE CONDITIONING DO ACQUIRE APPETITIVE DISCRIMINATIVE CONDITIONING}

Despite failing to discriminate the CSs in the aversive discrimination paradigm, all of the "failed" group animals $(n=6)$ successfully acquired discriminatory behavioral (head jerks) and cardiovascular (BP) responses to the same CSs in the appetitive condition $\left[\mathrm{CS}^{+}\right.$vs. $\mathrm{CS}^{-}$, behavior: $t_{(9-18)}>2.26, p<0.05$, BP: $t_{(9-18)}>2.17, p<0.05$, for each animal] (Supplementary Figures $2 \mathrm{~A}, \mathrm{~B})$, with a mean number of $14.33(\mathrm{SEM}=2.85) \mathrm{CS}^{+}$ trials to reach the criterion. Moreover, their rate of learning was within the normal range of all other marmosets in the colony previously trained on this appetitive task $(n=23, M=16.35$, SEM = 2.12) (Supplementary Figure 3).

\section{ANIMALS THAT FAIL TO ACQUIRE AVERSIVE DISCRIMINATIVE CONDITIONING EXHIBIT A HEIGHTENED ANXIETY-RELATED EMOTIONAL RESPONSE TO A RUBBER SNAKE}

When presented with a rubber snake, the "failed" group displayed behavioral patterns that indicated heightened fear and anxiety, compared to that of the "passed" group (Supplementary Table 3). A PCA revealed two principal components (rotated; 


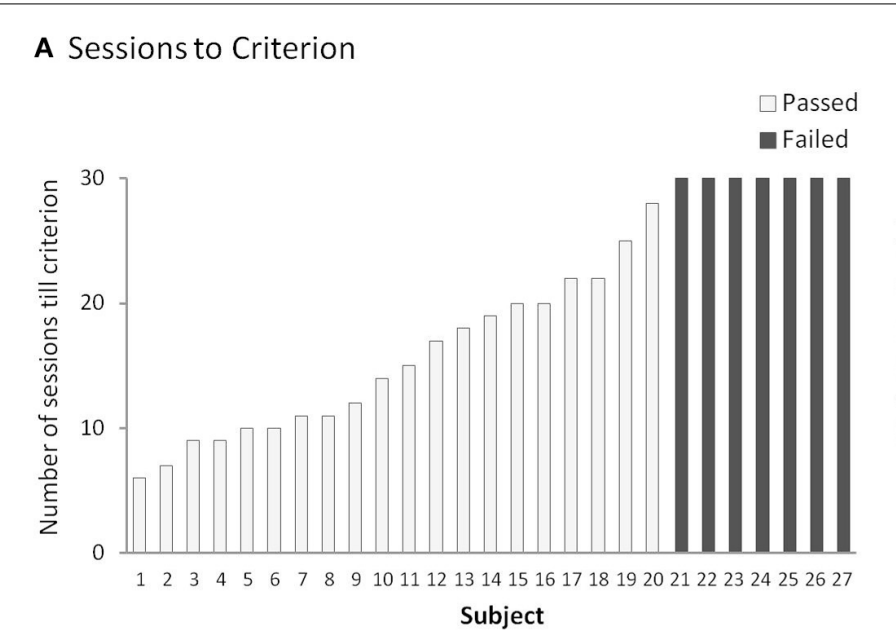

B Responses at Criterion

i Vigilant scanning
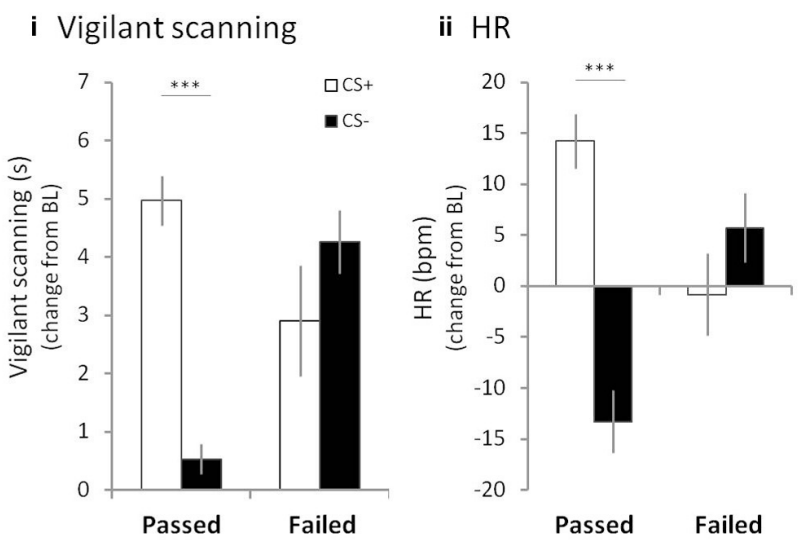

\section{Responses in Early Conditioning}

i Cue-associated vigilance (session 1-3)

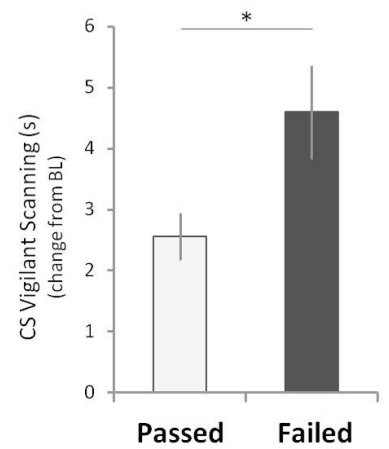

ii BL-associated BP reduction (session 1-9)

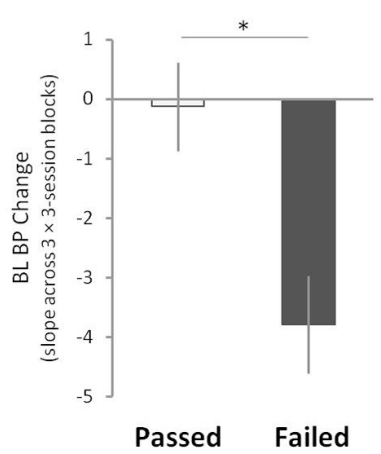

D Final Regression Model Predicting Discriminative Conditioning Performance

\begin{tabular}{lcccccc}
\hline $\begin{array}{l}\text { Retained } \\
\text { predictor }\end{array}$ & $\mathrm{B}$ & $\begin{array}{c}\text { Standard } \\
\text { Error }\end{array}$ & $\begin{array}{c}\text { Wald's } \\
\chi^{2}\end{array}$ & $d f$ & $P$ & $\begin{array}{c}\mathrm{eB} \\
\text { (odds ratio) }\end{array}$ \\
\hline Constant & -4.64 & 1.82 & 6.48 & 1 & .011 & 0.01 \\
$\begin{array}{l}\text { CS Vigilant } \\
\begin{array}{l}\text { Scanning } \\
\text { (Sessions 1-3) }\end{array}\end{array}$ & 0.66 & 0.38 & 2.98 & 1 & .084 & 1.93 \\
$\begin{array}{l}\text { BL BP } \\
\text { Reduction } \\
\text { (Sessions 1-9) }\end{array}$ & -0.57 & 0.28 & 3.96 & 1 & .047 & 0.57 \\
\hline
\end{tabular}

FIGURE 3 | Mild Aversive Pavlovian Discriminative Conditioning. (A) The number of sessions that each subject in the "passed" (open bar) group (1-20) took to reach the criterion of significantly higher vigilant scanning and HR to the $\mathrm{CS}^{+}$compared to the $\mathrm{CS}^{-}$, across a series of three consecutive sessions. The "failed" (filled bar) group (subjects 21-27) had still failed to reach criterion by the 30th session. (B) Responses to the $\mathrm{CS}^{+}$and $\mathrm{CS}^{-}$, compared to $\mathrm{BL}$ in the three discrimination criterion sessions for the "passed" group and sessions 28-30 for the "failed group" for (Bi) mean vigilant scanning scores, and (Bii) mean HR. Error bars show standard error of the mean (SEM). (C) "Passed" and "failed" group comparison of (Ci) mean cue-associated vigilant scanning scores during sessions 1-3 and, (Cii) mean BL-associated hypotension measures during sessions 1-9. Error bars show SEM. (D) Of the three variables inserted into the logistic regression analysis, the

cue-associated vigilance and BL-associated hypotension were retained in the final model as predictors of passing or failing the aversive discrimination. The positive coefficients for the CS vigilant behavior in sessions 1-3 indicated that as the vigilant behavior score increased by one unit, the odds of failing the discrimination increased from 1.0 to 1.93 . On the other hand, the negative coefficient $\beta$ indicated that as the BL BP measure declined by one unit, the odds of passing the discrimination decreased from 1.0 to 0.57 . Thus, the greater BL BP decline, the more likely the animal was to fail the discrimination. ${ }^{*} p<0.05$ for "passed" vs. "failed," $* * * p<0.001$ for $\mathrm{CS}^{+}$vs. $\mathrm{CS}^{-}$. with an eigenvalue over 1.00) accounting for $68.33 \%$ of the total variance (Figure 4A). The variables loading highly on component 1 included distance from the snake, total stare duration, locomotion and number of head-cocks. Animals with higher component 1 scores maintained a considerable distance from the snake, avoided staring at the snake, displayed reduced locomotion and head-cocks. These are indicative of high anxiety/emotionality, a pattern of behavior displayed by the "failed" group $\left[F_{(1,11)}=35.24, p<0.001\right]$ (Figures 4B,C). The behaviors loading highly on component 2 were stare frequency and tsik and tsik-egg calls that are emitted only in the presence of a predator threat and used to drive the threat away (Bezerra and Souto, 2008; Clara et al., 2008). Animals with higher component
2 scores emitted greater numbers of calls and displayed a higher frequency of short latency "looks" at the snake, behaviors which are hypothesized overall to contribute to a proactive coping strategy (Koolhaas et al., 1999; Cross and Rogers, 2006). This measure did not differ significantly between the groups ("passed": $M=0.37, \mathrm{SEM}=0.30$, "failed" $M=1.18, \mathrm{SEM}=$ $0.64)\left[F_{(1,11)}=1.45, p=0.254\right]$ (Supplementary Figure 4). Nor did the groups differ in their distance and locomotion scores in the other test phases in the absence of the snake [Average distance: "Separated" $t_{(11)}=-0.31, p=0.763$; "Pre-snake" $t_{(11)}=-0.29$, $p=0.774$; "Snake" $t_{(11)}=-3.31, \quad p<0.001$; "Post-snake" $t_{(11)}=-1.71, p=0.116$, Locomotion: "Separated" $t_{(11)}=0.01$, $p=0.993$; "Pre-snake" $t_{(11)}=1.77, \quad p=0.105$; "Snake" 


\section{A Component Loadings}

\begin{tabular}{|c|c|c|}
\hline \multirow[b]{2}{*}{ Measures } & \multicolumn{2}{|c|}{ Rotated Component Loadings } \\
\hline & $\begin{array}{l}\text { Component } 1 \\
\text { 'Emotionality' }\end{array}$ & $\begin{array}{c}\text { Component } 2 \\
\text { 'Coping Strategy' }\end{array}$ \\
\hline Average distance & .919 & .123 \\
\hline Stare duration & -.852 & .030 \\
\hline Locomotion & -.706 & -.035 \\
\hline Head-cock & -.638 & .164 \\
\hline Tsik call & .113 & .912 \\
\hline Tsik-egg call & .038 & .896 \\
\hline Stare frequency & -.257 & .726 \\
\hline Eigenvalues & 3.03 & 1.75 \\
\hline$\%$ of variance & 43.31 & 25.02 \\
\hline
\end{tabular}

\section{B Individual Differences}

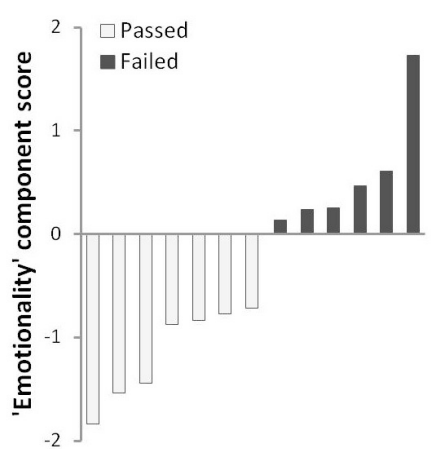

13461817312222324252126 Subject
C Group Comparison

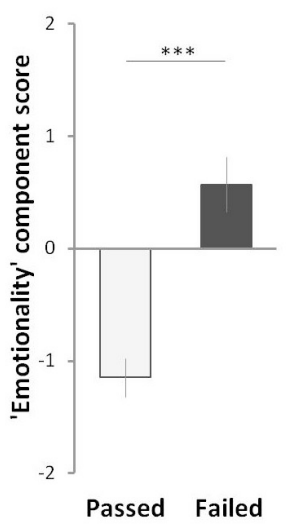

D Group Comparison of Average Distance and Locomotion across Phases

\begin{tabular}{|c|c|c|c|c|c|c|c|c|c|}
\hline & & \multicolumn{2}{|c|}{ Separated } & \multicolumn{2}{|c|}{ Pre-snake } & \multicolumn{2}{|c|}{ Snake } & \multicolumn{2}{|c|}{ Post-Snake } \\
\hline & & 'Passed' & 'Failed' & 'Passed' & 'Failed' & 'Passed' & 'Failed' & 'Passed' & 'Failed' \\
\hline Average distance $(\mathrm{cm})$ & Mean \pm SEM & $55.23 \pm 10.46$ & $60.21 \pm 12.45$ & $28.21 \pm 5.55$ & $30.99 \pm 7.90$ & $59.61 \pm 4.13$ & $84.61 \pm 6.61^{* *}$ & $44.18 \pm 5.63$ & $60.26 \pm 7.80$ \\
\hline Locomotion (\%) & Mean \pm SEM & $8.29 \pm 0.02$ & $8.26 \pm 0.02$ & $11.67 \pm 0.03$ & $6.25 \pm 0.01$ & $7.25 \pm 0.01$ & $3.16 \pm 0.01 *$ & $9.72 \pm 0.02$ & $6.97 \pm 0.01$ \\
\hline
\end{tabular}

FIGURE 4 | Rubber Snake Test. (A) Component loadings of the measures in the rubber snake test $(n=44)$. (B) "Emotionality" (principle component 1) score of each subject in the "passed" (open bar) and "failed" (filled bar) groups. Subject numbers correspond to the numbers in Figure 3A. (C) Comparison of mean "Emotionality" component scores between the "passed" and "failed" groups. Error bars show s.e.m. (D) Mean average distance and locomotion measures of the "passed" and "failed" groups across the four phases. ${ }^{*} p<0.05, * * p<0.01,{ }^{* * *} p<0.001$ for "passed" vs. "failed." $t_{(11)}=2.38, \quad p<0.05 ;$ "Post-snake" $\left.t_{(11)}=1.06, p=0.311\right]$ (Figure 4D).

\section{CUE-ASSOCIATED HYPER-VIGILANCE AND BL-ASSOCIATED REDUCTION IN BP ARE DIFFERENTIALLY CORRELATED WITH REDUCED PERSEVERATION ON antOFC- AND vLPFC-DEPENDENT COGNITIVE FLEXIBILITY TESTS}

In the antOFC-dependent flexibility test, all animals successfully learned to inhibit a prepotent response tendency and select the low-incentive food-box, rather than the high-incentive food-box. Comparison of the "passed" and "failed" groups for the total number of errors to reach the discrimination criterion returned a trend level difference $\left[t_{(11)}=1.87, p=0.089\right]$, this was due to a tendency for the "failed" group to make fewer errors (Figure 5Ai). There was considerable individual variation in the number of perseverative errors, a measure that has been shown to be affected by OFC lesions (Man et al., 2009), but this measure did not significantly differ between "passed" and "failed" groups $\left[t_{(11)}=1.31\right.$, $p=0.219]$ (Figure 5Ai).

Likewise, in the vlPFC-dependent flexibility test, all animals learned to refrain from reaching directly toward the visible food reward and instead, extrapolate the detour reaching rule from the opaque to the transparent box. Despite marked individual variation, "passed" and "failed" groups did not significantly differ in either the total number of errors (number of both "barrier reach" and "non-barrier reach" errors across first and second sessions) or the perseverative errors (number of "barrier reach" errors across first and second sessions), a measure that has been shown to be affected by vlPFC lesions (Wallis et al., 2001) [Three-Way factorial ANOVA of group $\times$ error type ("barrier reach"/"non-barrier reach") $\times$ session (1st/2nd): no main effect of group, $F_{(1,11)}=$ 2.31, $p=0.157$; no group $\times$ error type interaction, $F_{(1,11)}=$ $1.29, p=0.281$; no group $\times$ error type $\times$ session interaction, $\left.F_{(1,11)}=0.00, p=0.954\right]$ (Figure 5Bi).

The perseverative measures from the antOFC-dependent and vlPFC-dependent tasks did not correlate with each other [Person's $r=0.21, p=0.50$ ] (Supplementary Figure 5), which is consistent with the finding that performance on these two tests is differentially dependent upon two distinct regions of vPFC (Wallis et al., 2001; Man et al., 2009). However, perseverative responding on the two tests did correlate, differentially, with the two variables that predicted failure on the discrimination task. Specifically, perseverative responding on the antOFC-dependent test correlated negatively with cue-associated vigilance [Pearson's $r=-0.62, p<0.05]$ (Figure 5Aii), but not with BL-associated reduction in BP $[r=0.37, p=0.21]$ (Supplementary Figure 6) and importantly, the two correlations were significantly different from one another [Williams and Steiger test; $t=3.38$, $p<0.01]$. Conversely, perseverative responding on the vlPFCdependent test correlated negatively with BL-associated reduction in BP [Pearson's $r=-0.83, p<0.001$ ] (Figure 5Bii), but not with cue-associated vigilance [Pearson's $r=0.08, p=0.80$ ] (Supplementary Figure 7), and again the Williams and Steiger test confirmed that the correlations were significantly different $[t=2.84, p<0.05]$. Thus, the animals that displayed a heightened vigilance response to the CSs made fewer perseverative 


\section{A antOFC-dependent cognitive flexibility test}

i Number of Errors between the groups

\begin{tabular}{lcc}
\hline & 'Passed' & 'Failed' \\
\hline Total number of errors & $58.6 \pm 14.3$ & $27.0 \pm 7.3$ \\
Number of Perseverative Errors & $15.3 \pm 3.61$ & $10.0 \pm 1.10$ \\
\hline
\end{tabular}

ii Correlation with Cue-associated Vigilance

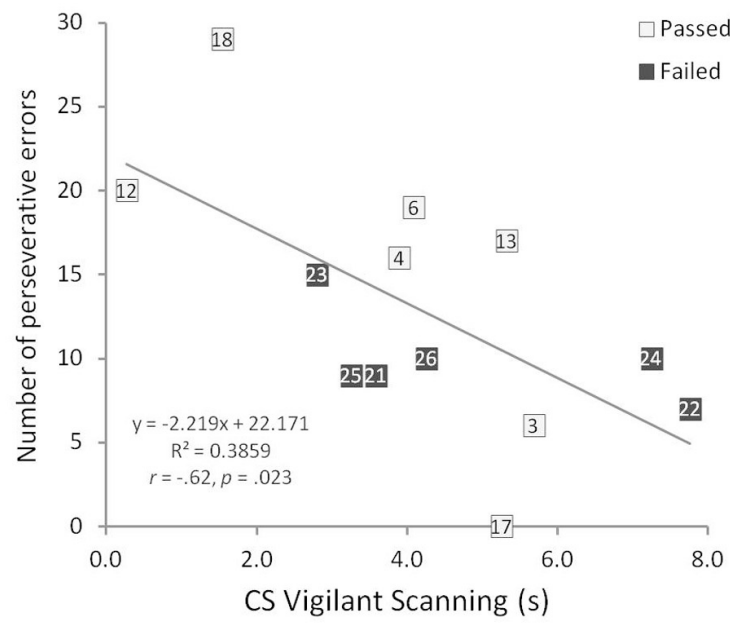

FIGURE 5 | Prefrontal-dependent Flexibility Tests. (A) antOFC-dependent cognitive flexibility test. (Ai) Comparison of "passed" and "failed" groups for the total number of errors and the number of perseverative errors (mean \pm s.e.m.). No significant group difference. (Aii) Significant negative correlation between the number of perseverative errors in the antOFC-dependent test and cue-associated vigilant scanning scores of the animals in the "passed" (open square) and "failed" (filled square) groups. Numbers in the squares correspond to the subject numbers in Figure 3A. (B) vIPFC-dependent
B VIPFC-dependent cognitive flexibility test

i Number of Errors between the groups

\begin{tabular}{lcc}
\hline & 'Passed' & 'Failed' \\
\hline $\begin{array}{l}\text { Total number of errors summed across } \\
1^{\text {st }} \text { and } 2^{\text {nd }} \text { sessions }\end{array}$ & $60.9 \pm 8.7$ & $45.7 \pm 6.5$ \\
$\begin{array}{l}\text { Number of 'Barrier Reach' Errors } \\
\text { summed across } 1^{\text {st }} \text { and } 2^{\text {nd }} \text { Sessions }\end{array}$ & $45.43 \pm 7.06$ & $33.67 \pm 2.64$ \\
\hline
\end{tabular}

ii Correlation with BL-associated BP Reduction

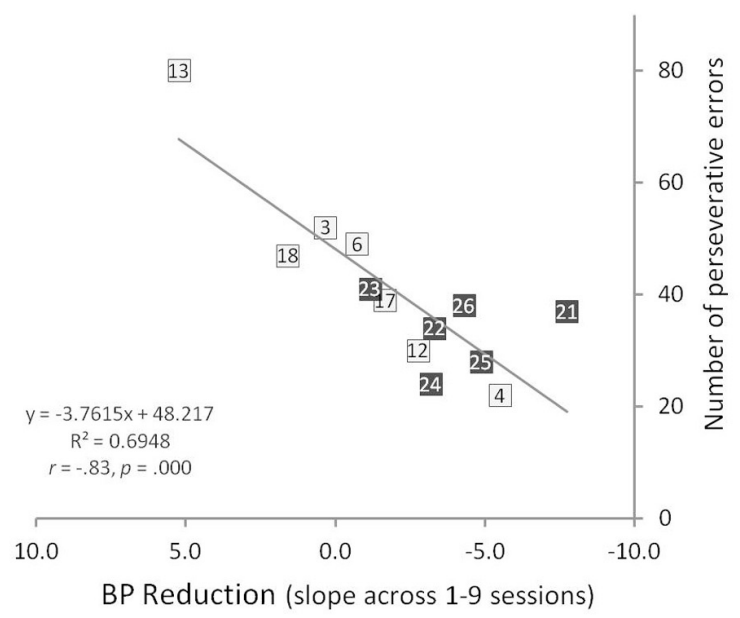

cognitive flexibility test. (Bi) Comparison of "passed" and "failed" groups for the total number of errors (both "barrier reach" and "non-barrier reach" errors) and the number of "barrier reach" errors summed across the first and second sessions. (Bii) Significant negative correlation between the number of perseverative "barrier reach" errors in the vIPFC-dependent test and BL-associated BP reduction of the animals in the "passed" and "failed" groups. The $x$-axis is flipped so that those with greater BP reduction are seen on the right side of the graph. errors specifically in the antOFC-dependent test, and those that displayed BL-associated reduction in BP made fewer perseverative responses specifically in the vlPFC-dependent test.

\section{DISCUSSION}

In a cohort of experimentally naive marmosets tested on a mild aversive discriminative conditioning paradigm, seven out of the 27 animals failed to show discriminative conditioned responses between the danger cue, $\mathrm{CS}^{+}$, and safety cue, $\mathrm{CS}^{-}$(Experiment 1 ). Consideration of their behavioral and cardiovascular responsivity during the early stage of discrimination training (before learning in the majority of animals had taken place) revealed that failure to discriminate was predicted either by a display of hypervigilance to both cues $\left(\mathrm{CS}^{+}\right.$and $\mathrm{CS}^{-}$) and/or the development of reduced $\mathrm{BP}$ during the $\mathrm{BL}$. Poor general learning abilities offer an unlikely explanation for the observed failure, given the animals in the "failed" group showed intact ability to acquire such discriminative responses in an appetitive setting. Instead, their failure is more likely due to high trait anxiety given that the "failed" group also showed heightened emotionality during the presentation of a predatory stimulus, a rubber snake, compared to the "passed" group (Experiment 2). Subsequent testing on two cognitive flexibility tests revealed an association between the two distinct behavioral and cardiovascular predictors of failed performance on the discrimination test and flexible cognitive performance (Experiment 3). Reduced perseverative performance was highly correlated with cue-associated hyper-vigilance on the antOFC-dependent flexibility task and with the BL-associated reduction in $\mathrm{BP}$ on the vlPFC-dependent flexibility task.

\section{ANXIETY-INDUCED FEAR GENERALIZATION}

Fear generalization is a feature of high trait anxiety (Reiss, 1997; Grillon, 2002) and a key symptom of clinical anxiety (Dunsmoor et al., 2011). In particular, a failure to display discriminative conditioned responses, and over-generalize instead, has been reported in patients suffering from panic disorder (Lissek et al., 2010), post-traumatic stress disorder (Grillon and Morgan, 1999; Mauchnik et al., 2010), and generalized anxiety disorder (Lissek et al., 2013). In comparison to relatively well documented studies in humans, very few studies involving 
animal models have addressed the association between failure to display discriminative conditioned responses and trait anxiety, apart from Duvarci et al. (2009) which reported a discriminative conditioning failure among rats with a high anxiety phenotype, as measured by performance on the elevated plus maze.

In the present study, even after a lengthy period of training, seven animals $(26 \%)$ were unable to discriminate between the $\mathrm{CS}^{+}$and $\mathrm{CS}^{-}$. It is unlikely that this reflects poor learning ability in general, as the same seven animals learned to discriminate between the same $\mathrm{CS}^{+}$and $\mathrm{CS}^{-}$when presented in an appetitive setting. Instead, their failure was more likely the result of fear generalization, either to the $\mathrm{CS}^{-}$(or safety signal) or to the overall context of the apparatus. Evidence for generalization of conditioned responses to the $\mathrm{CS}^{-}$is 2 -fold. First, by the end of conditioning the "failed" group displayed a similar magnitude of vigilance responses to both CSs. Second, upon initial exposure to the aversive loud noise (first three sessions) the animals that eventually failed to discriminate, displayed increased vigilant scanning and $\mathrm{HR}$ responses to both the $\mathrm{CS}^{+}$and $\mathrm{CS}^{-}$compared to the "passed" group, indicative of heightened emotionality in the presence of the aversive loud noise. In contrast, heightened responses to the same stimuli were not seen in the prior orienting sessions in which there was no aversive loud noise, although there was a trend for the "failed" group to show heightened vigilant scanning even in this period. These findings are consistent with the observation that high anxious individuals can show impairments in inhibiting fear responses to a safety signal (Grillon and Ameli, 2001). However, animals that subsequently failed the discrimination were also more likely to show a selective slowing of $\mathrm{HR}$ and decrease in BP during the BL period, across the first few conditioning sessions, compared to those that passed. Responses in the BL of a conditioning task usually reflect associative learning about the context, i.e., the apparatus in which the animal receives the unconditioned aversive stimulus, as distinct from any specific cues (Morgan and LeDoux, 1999; Grillon, 2008). Thus, the slowing of HR and decrease in BP that developed in the BL over the first nine sessions, as the "failed" animals received more and more pairings of the aversive loud noise, likely reflects generalized responding to the conditioning context. Whilst increased anxiety may have been predicted to induce increases rather than decreases in BP, a recent series of studies have reported associations between anxiety and lowered BP in young and elderly humans (Hildrum et al., 2008, 2011) and similarly, a negative association between worry-prone individuals and BP (Delgado et al., 2013).

Regression analysis revealed that of these different behavioral and cardiovascular measures relating to generalized responding to the safety cue and the context, heightened vigilant scanning to the $\mathrm{CS}^{-}$and reduced $\mathrm{BP}$ in the $\mathrm{BL}$ were the best predictors of discrimination failure, and were better together than on their own. Thus, these measures acted as biomarkers for eventual discrimination failure. In addition, these findings suggest that some animals may have failed to discriminate because they generalized their fear responses to the $\mathrm{CS}^{-}$whilst others may have failed to discriminate because they generalized their fear responses to the context. The hypothesis that such fear generalization was a consequence of being high in trait anxiety, was supported by the finding that this same group of animals showed increased emotionality in a completely distinct fear-provoking context, namely exposure to a rubber snake. Fear of snakes has been widely exploited in tests of anxiety both in humans and non-human primates (Öhman and Mineka, 2001). In marmosets, snakes are known to be their principle predators (Correa and Coutinho, 1997), and both captive-born and wild animals are known to exhibit a wide variety of emotive and defensive behaviors in their presence (Barros et al., 2002; Cross and Rogers, 2006; Clara et al., 2008; Cagni et al., 2011). In the present study the snake was presented in the animal's home cage environment surrounded by other conspecifics maximizing the ethological validity of the test. It should be noted that under these circumstances it cannot be ruled out that the animal's behavior to the snake may also have been influenced by the response of conspecifics. However, only the target animal could "see" the snake and thus any response of conspecifics was only in relation to the target animal's own behavior.

Upon encountering the snake stimulus, the animals that failed the discrimination, maintained a greater distance from the snake, showed reduced locomotion, as well as reduced numbers of headcocks and stare duration in comparison to the animals that passed the discrimination. In contrast, large numbers of head-cocks and prolonged stare duration were apparent in those animals that approached the snake and appear indicative of an investigative response. The finding that these measures were diminished in those animals that maintained the greatest distance from the snake likely reflects their overall heightened avoidance of the aversive stimulus. When all behavioral measures were placed into a principle component analysis, the variables that were apparently indicative of avoidance and anxiety were reduced into one component, which was accordingly labeled "emotionality." The "emotionality" scores were significantly higher in the "failed" animals than the "passed" animals. Thus, we demonstrate that the same animals displayed heightened emotionality across two very different paradigms, one involving learned fear and the other innate fear, consistent with the characteristics of a high anxiety trait. Moreover, the finding that some animals high in trait anxiety generalized to the safety cue in the fear discrimination task whilst others generalized to the context, suggests the existence of phenotypic variation within the high anxiety group, consistent with recent findings in rhesus monkeys with a high anxious temperament (Shackman et al., 2013).

\section{RELATIONSHIP OF TRAIT-LIKE ANXIETY WITH PFC-DEPENDENT COGNITIVE FLEXIBILITY}

Having established a model of trait-like anxiety in marmosets, the cognitive abilities associated with this trait were investigated. Previous studies of trait anxiety in humans have implicated altered functioning within the PFC. In particular, deficits in attentional mechanisms (Bishop et al., 2004), working memory and inhibitory control (Eysenck and Calvo, 1992; Fox, 1994) associated with dorsolateral PFC have been identified in individuals high in trait anxiety, primarily in the presence of anxiety provoking stimuli (but see Bishop, 2009). However, contrary findings have been reported in humans with the short allele of the serotonin transporter polymorphism, a gene associated with anxiety-related traits (Lesch et al., 1996; Hariri et al., 2005) and 
enhanced vulnerability to developing mood and anxiety disorders as a consequence of early-life stress (Caspi et al., 2003). In this case, improvements on certain prefrontal dependent tests have been reported. This has led to the proposal that the short allele is associated overall with an enhanced sensitivity to motivationally relevant stimuli (Belsky et al., 2009; Homberg and Lesch, 2011), which, in the case of positive stimuli can lead to improvements in performance, in contrast to the impairments seen for negative stimuli. Improvements, rather than impairments in response inhibition have also been reported during sustained anxiety (Robinson et al., 2013) in humans. In the present study we chose to investigate cognitive functioning dependent upon appetitive stimuli related to the ventral regions of PFC because (i) we have implicated ventral regions, in particular the OFC and vlPFC in marmosets, in the regulation of conditioned fear and anxiety (Agustín-Pavón et al., 2012) and (ii) altered functioning in vlPFC has been reported in humans with high trait anxiety performing a fear discrimination task (Indovina et al., 2011).

There were no overall significant differences in performance on the OFC- and vlPFC- dependent flexibility tests between those animals that displayed discriminative fear conditioning ("passed" group) and those that had not ("failed" group); despite there being a tendency for the latter, high anxious group to make fewer perseverative responses on both tests. The finding that perseverative responding on the two tests did not correlate with one another is not surprising since we have shown previously that the performance of marmosets on these two tests is dependent on two distinct ventral regions of PFC. However, detailed inspection of the data suggested that those animals that had shown the greatest generalization to the safety cue on the fear discrimination task (i.e., heightened cue-associated vigilance) displayed fewer perseverative errors on the appetitive OFC-dependent task. Of note, hyper-vigilance has also been proposed to increase sensitivity to both negative and positive events in the $s$-allele carriers of the anxiety-related serotonin transporter gene (Belsky et al., 2009; Homberg and Lesch, 2011). In contrast, those animals that showed generalization to the context (i.e., context-associated reduction in $\mathrm{BP}$ ) displayed fewer perseverative errors on the appetitive vlPFC-dependent test. Importantly, these effects were doubly dissociable, i.e., hyper-vigilance was correlated with OFCdependent task performance and not with vlPFC-dependent task performance, and BP reduction was correlated with vlPFCdependent task performance and not with OFC-dependent task performance. These findings support the hypothesis that the high anxiety trait may be associated with two distinct phenotypes and raises the intriguing possibility that these phenotypes may be related to altered functioning in distinct cognitive circuits associated with cued vs. contextual conditioning. Clearly such a hypothesis needs further testing with much larger n's than in the present study and with paradigms focusing on fearrelated cues and contexts. However, these findings do resonate, not only with evidence of phenotypic variation such as cortisol level and socio-emotional behaviors associated with altered neural activity in rhesus monkeys with high anxious temperament (Shackman et al., 2013) but also in a recent study proposing two independent neurocognitive dimensions underlying trait anxiety in humans (Indovina et al., 2011). Finally, these results also provide preliminary evidence that under some circumstances high trait-like anxiety may be associated with improved cognitive performance (as reported in humans) since those animals that displayed the greatest tendency to show generalized responding on the discrimination test (which were also those animals that showed greatest emotionality in response to the snake) had a tendency to show reduced perseverative responding, i.e., improved flexibility.

Studies of trait anxiety have so far revealed altered interactions not only between the ventral PFC and the amygdala (Indovina et al., 2011) and bed nucleus of the stria terminalis (Fox et al., 2010) but also the medial PFC and the amygdala (Kim et al., 2011). Changes in hippocampal metabolic activity have also been associated with an anxious temperament (Oler et al., 2010). Evidence is also accruing for a role of many of these same circuits in discriminative fear conditioning, especially in terms of safety signal learning (Kazama et al., 2012; Kong et al., 2014). Although other brain regions have also been implicated in safety learning including the insula (Christianson et al., 2011; Kong et al., 2014) and striatum (Schiller et al., 2008), whether changes in these structures are also associated with trait anxiety is less clear. Future studies should determine the differential contribution of these distinct prefronto-limbic-striatal circuits to emotion regulation especially in terms of their selective contributions to affective processing vs. more general contributions to information processing and decision making per se. Along with the recognition that altered activity within these distinct circuits underlie phenotypic variation within the high anxiety personality trait, such studies may provide insight into the nosology of anxiety and mood disorders.

In summary, we have identified individual differences in traitlike anxiety in marmosets based on their conditioned behavioral and cardiovascular fear responses on a Pavlovian discrimination task and their innate emotional responsivity to a rubber snake. Those marmosets that failed to discriminate between a conditioned fear and safety cue, and generalized instead to either the safety cue or the overall context, also displayed significantly greater anxiety and avoidance responses to the rubber snake. Regression analysis suggested the existence of two possible phenotypes within the high anxious group. Comparison of performance on two tests of cognitive flexibility dependent upon the OFC and vlPFC, respectively, revealed no significant differences. However, perseverative responding on the two tests correlated differentially with the cue-associated hyper-vigilance and context-associated reductions in BP displayed by the high anxious group on the discrimination task, further supporting the existence of phenotypic variation. We propose that this model will facilitate the study of distinct symptomatology and neural circuitry underlying trait anxiety, of relevance to our understanding of the nosology of anxiety disorders.

\section{ACKNOWLEDGMENTS}

This research was supported by a Medical Research Programme Grant (G0901884) from the Medical Research Council (MRC), UK to Angela C. Roberts. Yoshiro Shiba was supported by the Long Term Student Support Program provided by Osaka University and the Ministry of Education, Culture, Sports, Science 
and Technology of Japan and Andrea M. Santangelo, until October 2011, by a J. S. McDonnell Foundation grant (Principle Investigators; E. Phelps, T. W. Robbins, co-investigators; J. E. LeDoux, and Angela C. Roberts) and currently by the MRC Programme grant (G0901884). Work was carried out within the Behavioral and Clinical Neurosciences Institute supported by a consortium award from the Wellcome Trust and the MRC. We thank Drs. Hannah Clarke and Nicole Horst for helpful comments on an earlier draft. We also thank Dr. Yevheniia Mikheenko and Ms. Charrisa Kim for their help with behavioral scoring of the rubber snake test.

\section{SUPPLEMENTARY MATERIAL}

The Supplementary Material for this article can be found online at: http://www.frontiersin.org/journal/10.3389/fnbeh.2014. 00137/abstract

\section{REFERENCES}

Agustín-Pavón, C., Braesicke, K., Shiba, Y., Santangelo, A. M., Mikheenko, Y., Cockroft, G., et al. (2012). Lesions of ventrolateral prefrontal or anterior orbitofrontal cortex in primates heighten negative emotion. Biol. Psychiatry 72, 266-272. doi: 10.1016/j.biopsych.2012.03.007

Ahs, F., Pissiota, A., Michelgård, A., Frans, O., Furmark, T., Appel, L., et al. (2009). Disentangling the web of fear: amygdala reactivity and functional connectivity in spider and snake phobia. Psychiatry Res. 172, 103-108. doi: 10.1016/j.pscychresns.2008.11.004

Barros, M., Boere, V., Mello, E. L., and Tomaz, C. (2002). Reactions to potential predators in captive-born marmosets (Callithrix penicillata). Int. J. Primatol. 23, 443-454. doi: 10.1023/A:1013899931878

Belsky, J., Jonassaint, C., Pluess, M., Stanton, M., Brummett, B., and Williams, R. (2009). Vulnerability genes or plasticity genes? Mol. Psychiatry 14, 746-754. doi: $10.1038 / \mathrm{mp} .2009 .44$

Bezerra, B. M., and Souto, A. (2008). Structure and usage of the vocal repertoire of Int. J. Primatol. 29, 671-701. doi: 10.1007/s10764-008-9250-0

Bishop, S. J. (2007). Neurocognitive mechanisms of anxiety: an integrative account. Trends Cogn. Sci. 11, 307-316. doi: 10.1016/j.tics.2007.05.008

Bishop, S. J. (2009). Trait anxiety and impoverished prefrontal control of attention. Nat. Neurosci. 12, 92-98. doi: 10.1038/nn.2242

Bishop, S. J., Duncan, J., Brett, M., and Lawrence, A. D. (2004). Prefrontal cortical function and anxiety: controlling attention to threat-related stimuli. Nat. Neurosci. 7, 184-188. doi: 10.1038/nn1173

Bradley, B., and Mogg, K. (1999). Attentional bias for emotional faces in generalized anxiety disorder. Br. J. Clin. Psychol. 38, 267-278. doi: 10.1348/014466599162845

Braesicke, K., Parkinson, J. A., Reekie, Y., Man, M.-S., Hopewell, L., Pears, A., et al. (2005). Autonomic arousal in an appetitive context in primates: a behavioural and neural analysis. Eur. J. Neurosci. 21, 1733-1740. doi: 10.1111/j.14609568.2005.03987.x

Burman, K. J., Palmer, S. M., Gamberini, M., and Rosa, M. G. P. (2006). Cytoarchitectonic subdivisions of the dorsolateral frontal cortex of the marmoset monkey (Callithrix jacchus), and their projections to dorsal visual areas. J. Comp. Neurol. 495, 149-172. doi: 10.1002/cne.20837

Burman, K. J., and Rosa, M. G. P. (2009). Architectural subdivisions of medial and orbital frontal cortices in the marmoset monkey (Callithrix jacchus). J. Comp. Neurol. 514, 11-29. doi: 10.1002/cne.21976

Cagni, P., Sampaio, A. C., Ribeiro, N. B., and Barros, M. (2011). Immediate, but no delayed, behavioral response to a snake model by captive black tufted-ear marmosets. Behav. Processes 87, 241-245. doi: 10.1016/j.beproc.2011. 04.002

Cardinal, R. N., and Aitken, M. R. F. (2010). Whisker: a client-server highperformance multimedia research control system. Behav. Res. Methods 42, 1059-1071. doi: 10.3758/BRM.42.4.1059

Caspi, A., Sugden, K., Moffitt, T. E., Taylor, A., Craig, I. W., Harrington, H., et al. (2003). Influence of life stress on depression: moderation by a polymorphism in the 5-HTT gene. Science 301, 386-389. doi: 10.1126/science.1083968
Chambers, J. A., Power, K. G., and Durham, R. C. (2004). The relationship between trait vulnerability and anxiety and depressive diagnoses at long-term follow-up of Generalized Anxiety Disorder. J. Anxiety Disord. 18, 587-607. doi: 10.1016/j.janxdis.2003.09.001

Christianson, J. P., Jennings, J. H., Ragole, T., Flyer, J. G. N., Benison, A. M., Barth, D. S., et al. (2011). Safety signals mitigate the consequences of uncontrollable stress via a circuit involving the sensory insular cortex and bed nucleus of the stria terminalis. Biol. Psychiatry 70, 458-464. doi: 10.1016/j.biopsych.2011.04.004

Cisler, J., and Koster, E. (2010). Mechanisms of attentional biases towards threat in anxiety disorders: an integrative review. Clin. Psychol. Rev. 30, 203-216. doi: 10.1016/j.cpr.2009.11.003

Clara, E., Tommasi, L., and Rogers, L. J. (2008). Social mobbing calls in common marmosets (Callithrix jacchus): effects of experience and associated cortisol levels. Anim. Cogn. 11, 349-358. doi: 10.1007/s10071-007-0125-0

Clarke, H. F., Dalley, J. W., Crofts, H. S., Robbins, T. W., and Roberts, A. C. (2004). Cognitive inflexibility after prefrontal serotonin depletion. Science 304, 878-880. doi: 10.1126/science.1094987

Correa, H. K. M., and Coutinho, P. E. G. (1997). Fatal attack of a pit viper, bothrops jararaca, on an infant buffy-tufted ear marmoset (Callithrix aurita). Nat. Hist. 38, 215-217. doi: 10.1007/BF02382010

Cross, N., and Rogers, L. J. (2006). Mobbing vocalizations as a coping response in the common marmoset. Horm. Behav. 49, 237-245. doi: 10.1016/j.yhbeh.2005. 07.007

Cyr, L., and Francis, K. (1992). Measures of clinical agreement for nominal and categorical data: the kappa coefficient. Comput. Biol. Med. 22, 239-246. doi: 10.1016/0010-4825(92)90063-S

Delgado, L. C., Vila, J., and Reyes del Paso, G. A. (2013). Proneness to worry is negatively associated with blood pressure and baroreflex sensitivity: further evidence of the blood pressure emotional dampening hypothesis. Biol. Psychol. 96, 20-27. doi: 10.1016/j.biopsycho.2013.11.005

Dunsmoor, J. E., Prince, S. E., Murty, V. P., Kragel, P. A., and LaBar, K. S. (2011). Neurobehavioral mechanisms of human fear generalization. Neuroimage 55, 1878-1888. doi: 10.1016/j.neuroimage.2011.01.041

Duvarci, S., Bauer, E. P., and Pare, D. (2009). The bed nucleus of the stria terminalis mediates inter-individual variations in anxiety and fear. J. Neurosci. 29, 10357-10361. doi: 10.1523/JNEUROSCI.2119-09.2009

Eysenck, M. W., and Calvo, M. G. (1992). Anxiety and performance: the processing efficiency theory. Cogn. Emot. 6, 409-434. doi: 10.1080/02699939208 409696

Fedorchak, P. M., and Bolles, R. C. (1986). Differential outcome effect using a biologically neutral outcome difference. J. Exp. Psychol. Anim. Behav. Process. 12, 125-130. doi: 10.1037//0097-7403.12.2.125

Field, A. P. (2009). Discovering Statistics Using SPSS: (and Sex, Drugs and Rock " $n$ " Roll), $3 r d$ Edn. Los Angeles: SAGE Publications. Available online at: http://www. uk.sagepub.com/field3e/main.htm.

Fox, A. S., Shelton, S. E., Oakes, T. R., Converse, A. K., Davidson, R. J., and Kalin, N. H. (2010). Orbitofrontal cortex lesions alter anxiety-related activity in the primate bed nucleus of stria terminalis. J. Neurosci. 30, 7023-7027. doi: 10.1523/JNEUROSCI.5952-09.2010

Fox, E. (1994). Attentional bias in anxiety: a defective inhibition hypothesis. Cogn. Emot. 8, 165-195. doi: 10.1080/02699939408408934

Gaudry, E., Vagg, P., and Spielberger, C. (1975). Validation of the statetrait distinction in anxiety research. Behav. Res. 10, 331-341. doi: $10.1207 /$ s15327906mbr1003_6

Grillon, C. (2002). Associative learning deficits increase symptoms of anxiety in humans. Biol. Psychiatry 51, 851-858. doi: 10.1016/S0006-3223(01)01370-1

Grillon, C. (2008). Models and mechanisms of anxiety: evidence from startle studies. Psychopharmacology (Berl). 199, 421-437. doi: 10.1007/s00213-007-1019-1

Grillon, C., and Ameli, R. (2001). Conditioned inhibition of fear-potentiated startle and skin conductance in humans. Psychophysiology 38, 807-815. doi: 10.1111/1469-8986.3850807

Grillon, C., and Morgan, C. A. (1999). Fear-potentiated startle conditioning to explicit and contextual cues in Gulf War veterans with posttraumatic stress disorder. J. Abnorm. Psychol. 108, 134-142. doi: 10.1037/0021-843X.108.1.134

Hahn, A., Stein, P., Windischberger, C., Weissenbacher, A., Spindelegger, C., Moser, E., et al. (2011). Reduced resting-state functional connectivity between amygdala and orbitofrontal cortex in social anxiety disorder. Neuroimage 56, 881-889. doi: 10.1016/j.neuroimage.2011.02.064 
Hariri, A. R., Drabant, E. M., Munoz, K. E., Kolachana, B. S., Mattay, V. S., Egan, M. F., et al. (2005). A susceptibility gene for affective disorders and the response of the human amygdala. Arch. Gen. Psychiatry 62, 146-152. doi: 10.1001/archpsyc.62.2.146

Hildrum, B., Mykletun, A., Holmen, J., and Dahl, A. A. (2008). Effect of anxiety and depression on blood pressure: 11-year longitudinal population study. $\mathrm{Br}$. J. Psychiatry 193, 108-113. doi: 10.1192/bjp.bp.107.045013

Hildrum, B., Romild, U., and Holmen, J. (2011). Anxiety and depression lowers blood pressure: 22-year follow-up of the population based HUNT study, Norway. BMC Public Health 11:601. doi: 10.1186/1471-2458-11-601

Homberg, J. R., and Lesch, K.-P. (2011). Looking on the bright side of serotonin transporter gene variation. Biol. Psychiatry 69, 513-519. doi: 10.1016/j.biopsych.2010.09.024

Indovina, I., Robbins, T. W., Núñez-Elizalde, A. O., Dunn, B. D., and Bishop, S. J. (2011). Fear-conditioning mechanisms associated with trait vulnerability to anxiety in humans. Neuron 69, 563-571. doi: 10.1016/j.neuron.2010. 12.034

Izquierdo, A., and Murray, E. A. (2004). Combined unilateral lesions of the amygdala and orbital prefrontal cortex impair affective processing in rhesus monkeys. J. Neurophysiol. 91, 2023-2039. doi: 10.1152/jn.00968.2003

Kazama, A. M., Heuer, E., Davis, M., and Bachevalier, J. (2012). Effects of neonatal amygdala lesions on fear learning, conditioned inhibition, and extinction in adult macaques. Behav. Neurosci. 126, 392-403. doi: 10.1037/a0028241

Killgore, W. D. S., Britton, J. C., Schwab, Z. J., Price, L. M., Weiner, M. R., Gold, A. L., et al. (2013). Cortico-limbic responses to masked affective faces across ptsd, panic disorder, and specific phobia. Depress. Anxiety 10, 1-10. doi: $10.1002 /$ da. 22156

Kim, M. J., Loucks, R. A., Palmer, A. L., Brown, A. C., Solomon, K. M., Marchante, A. N., et al. (2011). The structural and functional connectivity of the amygdala: from normal emotion to pathological anxiety. Behav. Brain Res. 223, 403-410. doi: 10.1016/j.bbr.2011.04.025

Kim, M., and Whalen, P. (2009). The structural integrity of an amygdalaprefrontal pathway predicts trait anxiety. J. Neurosci. 29, 11614-11618. doi: 10.1523/JNEUROSCI.2335-09.2009

Kong, E., Monje, F. J., Hirsch, J., and Pollak, D. D. (2014). Learning not to fear: neural correlates of learned safety. Neuropsychopharmacology 39, 515-527. doi: 10.1038/npp.2013.191

Koolhaas, J. M., Korte, S. M., De Boer, S. F., Van der Vegt, B. J., Van Reenen, C. G., Hopster, H., et al. (1999). Coping styles in animals: current status in behavior and stress-physiology. Neurosci. Biobehav. Rev. 23, 925-935. doi: 10.1016/S01497634(99)00026-3

Lesch, K. P., Bengel, D., Heils, A., Sabol, S. Z., Greenberg, B. D., Petri, S., et al. (1996). Association of anxiety-related traits with a polymorphism in the serotonin transporter gene regulatory region. Science 274, 1527. doi: 10.1126/ science.274.5292.1527

Lissek, S., Kaczkurkin, A. N., Rabin, S., Geraci, M., Pine, D. S., and Grillon, C. (2013). Generalized anxiety disorder is associated with overgeneralization of classically conditioned fear. Biol. Psychiatry. doi: 10.1016/j.biopsych.2013. 07.025. [Epub ahead of print].

Lissek, S., Rabin, S., Heller, R. E., Lukenbaugh, D., Geraci, M., Pine, D. S., et al. (2010). Overgeneralization of conditioned fear as a pathogenic marker of panic disorder. Am. J. Psychiatry 167, 47-55. doi: 10.1176/appi.ajp.2009.09030410

Machado, C. J., Kazama, A. M., and Bachevalier, J. (2009). Impact of amygdala, orbital frontal, or hippocampal lesions on threat avoidance and emotional reactivity in nonhuman primates. Emotion 9, 147-163. doi: 10.1037/ a0014539

Macmillan, A. N., and Creelman, C. D. (2005). Detection Theory A User's Guide, 2nd Edn. New Jersey, NJ: Lawrence Erlbaum Associations, Inc.

Man, M. S., Clarke, H. F., and Roberts, A. C. (2009). The role of the orbitofrontal cortex and medial striatum in the regulation of prepotent responses to food rewards. Cereb. Cortex 19, 899-906. doi: 10.1093/cercor/ bhn 137

Mathews, A., Richards, A., and Eysenck, M. (1989). Interpretation of homophones related to threat in anxiety states. J. Abnorm. Psychol. 98, 31-34. doi: 10.1037/0021-843X.98.1.31

Mauchnik, J., Ebner-Priemer, U. W., Bohus, M., and Schmahl, C. (2010). Classical conditioning in borderline personality disorder with and without posttraumatic stress disorder. Z. Psychol./J. Psychol. 218, 80-88. doi: 10.1027/00443409/a000015
Mikheenko, Y., Man, M.-S., Braesicke, K., Johns, M. E., Hill, G., Agustín-Pavón, C., et al. (2010). Autonomic, behavioral, and neural analyses of mild conditioned negative affect in marmosets. Behav. Neurosci. 124, 192-203. doi: 10.1037/a0018868

Morgan, M. A., and LeDoux, J. E. (1999). Contribution of ventrolateral prefrontal cortex to the acquisition and extinction of conditioned fear in rats. Neurobiol. Learn. Mem. 72, 244-251. doi: 10.1006/nlme.1999.3907

Nelson, E. E., Shelton, S. E., and Kalin, N. H. (2003). Individual differences in the responses of naïve rhesus monkeys to snakes. Emotion 3, 3-11. doi: 10.1037/1528-3542.3.1.3

Oga, T., Aoi, H., Sasaki, T., Fujita, I., and Ichinohe, N. (2013). Postnatal development of layer III pyramidal cells in the primary visual, inferior temporal, and prefrontal cortices of the marmoset. Front. Neural Circuits 7:31. doi: 10.3389/fncir.2013.00031

Öhman, A., and Mineka, S. (2001). Fears, phobias, and preparedness: toward an evolved module of fear and fear learning. Psychol. Rev. 108, 483-522. doi: 10.1037//0033-295X.108.3.483

Oler, J. A., Fox, A. S., Shelton, S. E., Rogers, J., Dyer, T. D., Davidson, R. J., et al. (2010). Amygdalar and hippocampal substrates of anxious temperament differ in their heritability. Nature 466, 864-868. doi: 10.1038/nature09282

Pistorio, A. L., Vintch, B., and Wang, X. (2006). Acoustic analysis of vocal development in a New World primate, the common marmoset (Callithrix jacchus). J. Acoust. Soc. Am. 120, 1655. doi: 10.1121/1.2225899

Price, J. L. (1999). Prefrontal cortical networks related to visceral function and mood. Ann. N.Y. Acad. Sci. 877, 383-396. doi: 10.1111/j.17496632.1999.tb09278.x

Reekie, Y. L., Braesicke, K., Man, M. S., and Roberts, A. C. (2008). Uncoupling of behavioral and autonomic responses after lesions of the primate orbitofrontal cortex. Proc. Natl. Acad. Sci. U.S.A. 105, 9787-9792. doi: 10.1073/pnas.0800417105

Reiss, S. (1997). Trait anxiety: it's not what you think it is. J. Anxiety Disord. 11, 201-214. doi: 10.1016/S0887-6185(97)00006-6

Richards, A., French, C. C., Calder, A. J., Webb, B., Fox, R., and Young, A. W. (2002). Anxiety-related bias in the classification of emotionally ambiguous facial expressions. Emotion 2, 273-287. doi: 10.1037//1528-3542.2.3.273

Roberts, A. C., Tomic, D. L., Parkinson, C. H., Roeling, T. A., Cutter, D. J., Robbins, T. W., et al. (2007). Forebrain connectivity of the prefrontal cortex in the marmoset monkey (Callithrix jacchus): an anterograde and retrograde tract-tracing study. J. Comp. Neurol. 502, 86-112. doi: 10.1002/cne.21300

Robinson, O. J. O., Krimsky, M., and Grillon, C. (2013). The impact of induced anxiety on response inhibition. Front. Hum. Neurosci. 7:69. doi: 10.3389/fnhum.2013.00069

Sandi, C., and Richter-Levin, G. (2009). From high anxiety trait to depression: a neurocognitive hypothesis. Trends Neurosci. 32, 312-320. doi: 10.1016/j.tins.2009.02.004

Sasaki, E., Suemizu, H., Shimada, A., Hanazawa, K., Oiwa, R., Kamioka, M., et al. (2009). Generation of transgenic non-human primates with germline transmission. Nature 459, 523-527. doi: 10.1038/nature08090

Schiller, D., Levy, I., Niv, Y., LeDoux, J. E., and Phelps, E. A. (2008). From fear to safety and back: reversal of fear in the human brain. J. Neurosci. 28, 11517-11525. doi: 10.1523/JNEUROSCI.2265-08.2008

Shackman, A. J., Fox, A. S., Oler, J. A., Shelton, S. E., Davidson, R. J., and Kalin, N. H. (2013). Neural mechanisms underlying heterogeneity in the presentation of anxious temperament. Proc. Natl. Acad. Sci. U.S.A. 110, 6145-6150. doi: 10.1073/pnas.1214364110

Shin, L. M., Wright, C. I., Cannistraro, P. A., Wedig, M. M., McMullin, K., Martis, B., et al. (2005). A functional magnetic resonance imaging study of amygdala and medial prefrontal cortex responses to overtly presented fearful faces in posttraumatic stress disorder. Arch. Gen. Psychiatry 62, 273-281. doi: 10.1001/archpsyc.62.3.273

Stevens, J. S., Jovanovic, T., Fani, N., Ely, T. D., Glover, E. M., Bradley, B., et al. (2013). Disrupted amygdala-prefrontal functional connectivity in civilian women with posttraumatic stress disorder. J. Psychiatr. Res. 47, 1469-1478. doi: 10.1016/j.jpsychires.2013.05.031

Tardif, S., and Smucny, D. (2003). Reproduction in captive common marmosets (Callithrix jacchus). Comp. Med. 53, 364-368.

Thomas, K. M., Drevets, W. C., Dahl, R. E., Ryan, N. D., Birmaher, B., Eccard, C. H., et al. (2001). Amygdala response to fearful faces in anxious and depressed children. Arch. Gen. Psychiatry 58, 1057-1063. doi: 10.1001/archpsyc.58.11.1057 
Visu-Petra, L., Miclea, M., and Visu-Petra, G. (2012). Individual differences in anxiety and executive functioning: a multidimensional view. Int. J. Psychol. 48, 649-659. doi: 10.1080/00207594.2012.656132

Wallis, J. D., Dias, R., Robbins, T. W., and Roberts, A. C. (2001). Dissociable contributions of the orbitofrontal and lateral prefrontal cortex of the marmoset to performance on a detour reaching task. Eur. J. Neurosci. 13, 1797-1808. doi: 10.1046/j.0953-816x.2001.01546.x

Yeterian, E. H., Pandya, D. N., Tomaiuolo, F., and Petrides, M. (2012). The cortical connectivity of the prefrontal cortex in the monkey brain. Cortex 48, 58-81. doi: 10.1016/j.cortex.2011.03.004

Conflict of Interest Statement: The authors declare that the research was conducted in the absence of any commercial or financial relationships that could be construed as a potential conflict of interest.
Received: 28 February 2014; accepted: 03 April 2014; published online: 24 April 2014. Citation: Shiba Y, Santangelo AM, Braesicke K, Agustín-Pavón C, Cockcroft G, Haggard $M$ and Roberts AC (2014) Individual differences in behavioral and cardiovascular reactivity to emotive stimuli and their relationship to cognitive flexibility in a primate model of trait anxiety. Front. Behav. Neurosci. 8:137. doi: 10.3389/fnbeh. 2014.00137

This article was submitted to the journal Frontiers in Behavioral Neuroscience.

Copyright (C) 2014 Shiba, Santangelo, Braesicke, Agustín-Pavón, Cockcroft, Haggard and Roberts. This is an open-access article distributed under the terms of the Creative Commons Attribution License (CC BY). The use, distribution or reproduction in other forums is permitted, provided the original author(s) or licensor are credited and that the original publication in this journal is cited, in accordance with accepted academic practice. No use, distribution or reproduction is permitted which does not comply with these terms. 